\title{
Observations on Concussion
}

\author{
A Review \\ J.M.S. Pearce \\ Emeritus Consultant Neurologist, Department of Neurology, Hull Royal Infirmary, Hull, UK
}

\section{Key Words}

Concussion, definitions of $\cdot$ Commotio cerebri .

Mild traumatic brain injury

\begin{abstract}
The word 'concussion' has several meanings and applications that are controversial. This paper attempts to trace the historical origins and evolution of the descriptive classifications of concussive head injuries. It is suggested that head injuries should be described on the available evidence of the severity and duration of altered consciousness, traumatic amnesia and, when present, the variably associated neurological, physiological and imaging signs. The word concussion reflects an overenthusiastic trend in medical labelling. Since our understanding of types of brain injury and their symptoms and sequelae has advanced, the term should be abandoned.

Copyright $\odot 2007$ S. Karger AG, Base
\end{abstract}

\section{Introduction}

Mild head injuries have posed difficulties in definition and consequently in understanding their pathogenesis and their treatment. So-called 'concussion' affects about 128 people per 100,000 population in the United States per year [1]. The word concussion has been applied to milder injuries and is the focus of this paper. The word originates in the Latin stem of concutere, to dash together, shake violently; it says nothing of the clinical or pathological con-

\section{KARGER}

Fax +4161306 1234 E-Mail karger@karger.ch www.karger.com
(C) 2007 S. Karger AG, Basel

0014-3022/08/0594-0113\$24.50/0

Accessible online at:

www.karger.com/ene sequences. Modern dictionaries vary widely in their quality and precision; some define concussion in relation to the blow or impacting force, others to the resulting pathological injury to the brain and others to the alteration of memory or consciousness [2] (table 1). Concussion is used as equivalent to the older commotio cerebri.

The nature of coma, stupor and confusion, as alterations of consciousness after head injury has been recognised since the Edwin Smith Papyrus, a copy of an ancient (17000 BC) composite manuscript. The papyrus contained, in addition to the original author's text (30002500 BC), a commentary added a few hundred years later in the form of 69 explanatory notes (glosses) [8]; 27 of the 48 cases described in the Papyrus were examples of head trauma.

De Vulneribus Capitis [9] is a short Hippocratic text where injuries are described in relation to the apparent damage to scalp and skull, with little attention to brain injury. Aphorism no. 58 from Section 7 described:

'Shaking or concussion of the brain produced by any cause inevitably leaves the patient with an instantaneous loss of voice' [implying unconsciousness].

Flamm [10] provided an excellent illustrated historical account of serious injuries in connection with the dilated pupil, the significance of which was not appreciated until the late 19th century. Trephination was performed if there was no obvious depressed or penetrating injury or fracture. Elevation of depressed fractures was established before the 16th century and elegantly illustrated by woodcuts in Hans von Gersdorff's well-known Feldbuch der
J.M.S. Pearce

304 Beverley Road

Anlaby, East Yorks, HU10 7BG (UK) 
Wundartznei (1517) [11]. Much later, Vidius (1509-1569), Fallopius (1523-1562) and Ambroise Paré (1510-1590) all tended to follow the Hippocratic dictates relating to head injuries with altered consciousness.

The great Persian physician Rhazes (Ar-Razi c.860932 C.E.), at the Baghdad hospital is said to have first clarified concussion. (He also gave the first known description of smallpox.)

\section{Concussion: A Disorder of Function}

Concussion [12] was a word used by Berengario de Capri (1470-1530) [13], and by Ambroise Paré [14] in the 16th century, who spoke of concussion or commotio cerebri to describe the effects of brain injury when they found no skull fracture. Denny-Brown [12] quoted Boirel [15] as saying commotio was different from other traumatic effects on the cerebrum because it was of little intensity and short duration, which would not permit the possibility of cerebral lesions. This illustrates the traditional notion of concussion as a mild brain injury. Many subsequent 19th century writers [16] adopted this view. Koch and Filene [17] found that animals could be killed by repeated small impact blows to the head without there being any injury to the brain and agreed that concussion was due to shaking of nervous structures, but not to structural damage. Small blows would paralyse the respiratory, vasomotor and pupillary centres, one by one, and concussion was a generalised but transient consequence affecting all centres. Thus arose a concept of concussion as a disorder of function rather than an indicator of structural damage. Support was provided by Littré [18] who is credited with the first autopsy in a fatal head injury in which he found no structural lesions, and deduced commotio as distinct from haemorrhage or contusion. Vance [19] in 1927 reported 512 autopsies of fatal head injuries in which laceration and bruising were 'entirely lacking' in 16 cases. However, all these papers depended on fatal head injuries, which therefore do not conform to the traditional categorisation of concussion as a short-lived or transient disturbance of the brain.

\section{Concussion: Pathological Brain Damage}

Yet there was evidence in the 19th century of cases when more advanced neuropathology showed cerebral lesions that did complicate concussion. In 1831, Richard Bright [20] described petechial haemorrhages in the brain

Table 1. Some definitions of concussion

Oxford English

Dictionary

\begin{tabular}{l} 
Ropper and \\
Gorson [1] \\
\hline The American \\
Heritage Science \\
Dictionary [2]
\end{tabular}

Trotter [3]

http://brain-
injurycom/little-
knownsymptoms.
html [4]

\section{Online medical} dictionary

http://cancerweb. ncl.ac.uk/cgi-bin/ omd?concussion

\section{Congress of} Neurological Surgeons, Committee on Head Injury Nomenclature [5]

\section{Denny-Brown}

[6]

Aubry et al. [7]

(1) The action of violently shaking or agitating; particularly, the shock of impact. (2) Injury caused to the brain, spine, or other part, by the shock of a heavy blow, fall, etc.

Concussion refers to an immediate and transient loss of consciousness accompanied by a brief period of amnesia after a blow to the head.

A violent blow followed by a temporary, sometimes prolonged, loss of function. A concussion of the brain results in transient loss of consciousness or memory.

An essentially transient state due to head injury which is of instantaneous onset, manifests widespread symptoms of purely paralytic kind, does not as such comprise any evidence of structural cerebral injury, and is always followed by amnesia for the actual moment of the accident.

A violent blow or impact and followed by a temporary, sometimes prolonged, loss of function. A concussion of the brain results in transient loss of consciousness or memory ... alteration of conscious awareness after head trauma.

Transient or prolonged unconsciousness with or without impairment of higher mental functions and/or brainstem functions, due to a violent blow to the head.

A clinical syndrome characterised by the immediate and transient post-traumatic impairment of neural function such as alteration of consciousness, disturbance of vision or equilibrium due to mechanical forces.

A disturbance of consciousness both immediate, consecutive, and remote. There appears to be an intimate link between amnesia and concussion so much so that if a patient claims no memory loss, it is unlikely that concussion has occurred.

A complex pathophysiological process affecting the brain, induced by traumatic biomechanical forces. ... Concussion results in a graded set of clinical syndromes that may or may not involve loss of consciousness. 
He believed that the displaced cerebrum forced the flow of cerebrospinal fluid through the aqueduct into the fourth ventricle, which struck its floor and there caused punctate haemorrhages. In 1878 , he noted frequent capillary bleeding in the medulla from a single fatal blow to the head, both in man and animals [21]. Berner [22] confirmed this and regarded such brainstem petechiae as important in the mechanism of concussion. But prolonged unconsciousness or deepening coma culminating in death could be considered effects of head injury of much greater magnitude than concussion. Fano [23] in 1853 described haemorrhagic lesions in fatal concussion; and Thomas Bryant [24] in his The Practice of Surgery in 1878, remarked: 'A concussed brain should be regarded as a bruised one'.

\section{Mechanisms}

Primary brain damage on impact can take two forms [25]:

(1) Cerebral contusions - focal bruising on the brain surface or diffuse, when the head as a whole decelerates, usually by striking an object. Contusions themselves do not necessarily cause impaired consciousness or focal neurological signs but may cause secondary oedema or bleeding.

(2) Diffuse axonal injury (DAI) - widespread tearing of the white matter fibres in the subcortical areas. This may be independent of contusions or fracture and usually causes immediate unconsciousness.

Secondary brain damage may result from hypoxia, raised pressure or infection, but is not part of the initial concussive mechanism.

In a scholarly dissertation, Denny-Brown [6] stressed the importance of traumatic amnesia:

'the most obvious change in concussion is a disturbance of consciousness both immediate, consecutive, and remote. There appears, he said, to be an intimate link between amnesia and concussion so much so that if a patient claims no memory loss, it is unlikely that concussion has occurred.'

After extensive experimentally induced head injuries in cats [26], he established a crucial mechanism, 'The nervous effect of a blow is thus considered to be due to the physical acceleration directly transmitted to each and every centre. The most satisfactory definition would appear to be that of Sir Wilfred Trotter [3]: "an essentially transient state due to head in jury which is of instantaneous onset, manifests widespread symptoms of purely para- lytic kind, does not as such comprise any evidence of structural cerebral injury, and is always followed by amnesia for the actual moment of the accident."'

Animal experiments by Denny-Brown and Russell [26] showed that the neural dysfunction of concussion resulted from an acceleration mechanism:

'Re-investigation of the phenomenon in cats under Nembutal anaesthesia confirms its appearance in severe degree, and ability to result in death, without macroscopic lesions of the brain stem.... Momentary deformity of the skull, and stimulation of superficial structures, therefore appear to play no part. ... The nervous effect of a blow is thus considered to be due to the physical acceleration directly transmitted to each and every centre.

In contrast to Symonds (vide infra) and some current opinions, Denny-Brown regarded cerebral concussion as a mild injury - when the subject is momentarily only dazed - as distinct from cerebral contusions and from certain delayed disturbances of consciousness related to syncope or increased intracranial pressure (haematomata, cerebral oedema), and from purely psychogenic disturbances of consciousness.

\section{Neuropathology}

Neuropathologists have long recognised neuronal damage, cerebral oedema and petechial haemorrhages in coma-producing and fatal brain injuries $[27,28]$. But only autopsied brains, not representative of minor or concussive injuries, could be studied at various times after injury. Sabina Strich's [29] study of white matter lesions years after non-fatal head injury and their relationship to posttraumatic dementia produced the notion of DAI. The lesions usually followed cranial acceleration and were found mainly at the junctions of white and grey matter. With Nevin [30], she believed that the lesions resulted from axonal shearing, between grey and white matter. Oedema and brainstem lesions complicated diffuse injury.

Subsequently, CT and MRI allowed diagnosis of diffuse white matter injury during life. The clinical results of diffuse axonal injury are complex. In mild DAI, the period of unconsciousness is, by definition, 6-24 h; recovery is often gradual, with drowsiness, confusion and post-traumatic amnesia. This group roughly correlates with more severe cases traditionally labelled 'concussion'. By contrast, in moderate and severe DAI, coma lasts longer than $24 \mathrm{~h}$, neurological and cognitive symptoms may continue into the recovery period, sometimes with lasting sequelae. If there is brain oedema or haematoma, DAI is accompanied by raised intracranial pressure. But 
these symptoms and their attendant gross pathology are generally classed as more severe than concussion, i.e. traumatic intra- or extra-cerebral haemorrhage in varying sizes and locations, or clinically as continuing rather than transient stupor or coma. Yet, these remain conventions to separate the more severe from the mild brain injury.

Current opinion is that concussion results from the disruption of the electrophysiological and subcellular activities of the neurons of the reticular activating system situated in the midbrain and diencephalon, where maximal rotational forces are exerted. Experimental injury in rodents shows that mild traumatic brain injury (MTBI) induces apoptotic cell death in the cortex that is preceded by decreases in the anti-cell-death protein Bcl-2 immunoreactivity. But animal studies cannot be exactly translated to human brain injury. Alternative mechanisms for concussive loss of consciousness, such as self-limited cortical seizures or a sudden increase in intracranial pressure, have also been proposed, but with limited supporting evidence.

\section{Definitions of Concussion}

The most significant effects of concussion are loss of awareness and traumatic amnesia [31,32]. Opinions are not uniform. For example, a questionnaire was recently sent to physicians at 105 emergency surgery, neurological and neurosurgery departments in Austria. Retrograde amnesia was given as the main criterion for concussion by 88 , loss of consciousness by 86 and post-traumatic amnesia (PTA) by $81 \%$ [33].

Definitions are generally qualified by the statement that the loss of consciousness can occur in the absence of any gross or microscopic cerebral damage [34]. Yet studies of amateur boxers after a bout, compared with the non-athletic control subjects, show significant but transient elevation of cerebrospinal fluid neurofilament light protein and glial fibrillary acidic protein. This indicates acute neuronal and astroglial injury can occur after relatively minor brain injuries [35], and confirms Sir Charles Symonds' [36] assertions that

'Symptoms could not be made to conform with any arbitrary limit of time taken for recovery of full consciousness, or indeed with the absence of sequelae. ...:

Concussion should not be confined to cases in which there is immediate loss of consciousness with rapid and complete recovery but should include the many cases in which the initial symptoms are the same but with subsequent long-continued disturbance of consciousness, often followed by residual symptoms ...
Concussion in the above sense depends upon diffuse injury to nerve cells and fibres sustained at the moment of the accident. The effects of this injury may or may not be reversible.'

Clinically concussion is now considered a sequel of brain injury produced by acceleration (or deceleration) of the head and is characterized by a sudden brief impairment of consciousness, paralysis of reflex activity [34] and loss of memory. However the strict borders of definition and the mechanisms of concussion [37] remain controversial.

In 1966, the Committee on Head Injury Nomenclature of the Congress of Neurological Surgeons widened the definition but demanded that impairments of neural function are transient, thus excluding (contrary to Symonds' view) those with prolonged unconsciousness or persisting neurological symptoms:

[concussion is] ' ... a clinical syndrome characterised by the immediate and transient [sic] post-traumatic impairment of neural function such as alteration of consciousness, disturbance of vision or equilibrium due to mechanical forces' [5].

This imprecise 'consensus' definition was widely accepted. The American Medical Association and the International Neurotraumatology Association subsequently endorsed it:

'A transitory and reversible nervous reaction with immediate onset following physical stress of sufficient violence and brevity, and characterized by progressive recovery thereafter.'

Four arbitrary stages were posited [38]:

Stage 1: Immediately after the injury; there may be a period of unconsciousness for seconds or minutes but the subject usually awakens spontaneously.

Stage 2: Following recovery of PTA (over 20-30 min); apparent deficits such as slowed information processing.

Stage 3: Clinical recovery; acute symptoms settle over several days.

Stage 4: Cognitive recovery; the clinical symptoms have fully resolved and the neuropsychological function returns to normal. This would typically vary from 3 to 4 days for a mild concussion up to 2-3 weeks for a severe concussion.

In 2001, the Concussion In Sports Group [7] attempted a definition of concussion, of limited value, that highlights rather than resolves the crucial problems:

'Concussion, a complex pathophysiological process affecting the brain, induced by traumatic biomechanical forces. Several common features that incorporate clinical, pathological, and biomechanical injury constructs that may be used in defining the nature of a concussive head injury include: 
Concussion may be caused by a direct blow to the head, face, neck, or elsewhere [sic] on the body with an 'impulsive' force transmitted to the head.

Concussion typically results in the rapid onset of short-lived impairment of neurological function that resolves spontaneously.

Concussion may result in neuropathological changes but the acute clinical symptoms largely reflect a functional disturbance rather than structural injury.

Concussion results in a graded set of clinical syndromes that may or may not involve loss of consciousness. Resolution of the clinical and cognitive symptoms typically follows a sequential course.

Concussion is typically associated with grossly normal structural neuroimaging studies' [7].

Importantly, they later reported, 'there is no existing animal or other experimental model that accurately reflects a sporting concussive injury' [39].

Kelly and Rosenberg [40] previously graded sports concussion within a useful but arbitrary framework with which to judge severity, but not definition:

Grade 1: confusion, lasting less than 15 min; Grade 2: transient amnesia or confusion, lasting more than 15 min; Grade 3a: brief (seconds) loss of consciousness; Grade 3b: prolonged (minutes) loss of consciousness.

An alternative but not precisely equivalent term currently in fashion is mild MTBI. The wide diagnostic criteria are:

'a person who has had a traumatically induced physiological disruption of brain function, as manifested by at least one of the following: Any period of loss of consciousness; any loss of memory for events before or after the accident; any alteration in mental state at the time of the accident (e.g. feeling dazed, disoriented, or confused); focal neurological deficit(s); post-traumatic amnesia not greater than $24 \mathrm{~h}$; Glasgow Coma Scale 13-15, and loss of consciousness of approximately $30 \mathrm{~min}$ or less' [41].

\section{Significance of Amnesia}

Denny-Brown's account illustrates the classic traditional feature of traumatic amnesia:

'In man, amnesia both retrograde and postgrade is its chief external sign, accompanied by a loss of reactivity which is its clearest feature in animals. The loss of activity affects all tissue subjected to such stress but the duration of [neural] paralysis varies with the complexity of the nervous mechanism as well as the intensity of injury' [6].

Some published opinions suggest that post-concussive symptoms may be more important than the presence or duration of amnesia alone [42-44]; yet this does not relate to the nature of concussion but to the sequelae of head injury. Further, retrograde amnesia varies with the time of its measurement after injury and does not accurately indicate the severity of brain dysfunction [45].

The most controversial issue - reflected in the diversity of definitions - remains the assertion that concussion may or may not involve loss of consciousness and memory. Ritchie Russell's [46] classic study of 200 patients reasonably concluded:

'If, after an accident, the victim does not remember the details of how it happened, up to and including the moment in which he was injured, it is probable that he has suffered from concussion, and careful inquiry of the first thing he remembered after the accident will often show that consciousness was lost for a few minutes....'

Most believe that even the mildest form of concussion is accompanied by some degree of impaired consciousness, confusion and/or amnesia $[1,4,21,23]$. Retrograde amnesia is variable, and the injury is rarely remembered. PTA is a function of injury severity $[47,48]$, but it is sometimes difficult to determine when consciousness has fully returned. Ritchie Russell [47] included PTA in the total period of traumatic impairment of consciousness:

'... The victim of an accident may be able to move and even to talk sensibly and yet have no subsequent memory of his words or actions. He is then in the post-traumatic amnesia (PTA). This failure to commit, initial post-traumatic actions and conversations to memory would indicate, that he had not recovered consciousness in full.'

He observed that untrained observers' assessments of return to full consciousness were of limited value. Determination of PTA duration is important, as it yields an index of injury severity and is one of the best predictors of recovery and functional outcome [47].

\section{Amnesia without Impairment of Consciousness?}

A further complicating issue is Fisher's [49] well-documented instance when a patient struck her head and was immediately rendered amnesic without a trace of unconsciousness or stupor. Another example was Blonstein and Clarke [50] who described a boxer who completed and won his bout but in the dressing room afterwards had amnesia for the whole contest and its sequelae. He had not been knocked out, nor had he been obviously 'out on his feet'.

Fisher commented that if the data are reliable, it must be concluded that a traumatic insult to the memory 
mechanism can occur with complete sparing of the neural basis of alertness. However, more often it is overlooked that recollection of the actual blow to the head is never present when a patient immediately loses consciousness. Many head injuries are unwitnessed; feeling dazed or appearing to have impaired consciousness are difficult to define consistently.

\section{Unanswered Questions}

Despite many publications these considerations leave several issues unanswered, notably: does being dazed, seeing stars or feeling dizzy in the absence of unconsciousness constitute either concussion or MTBI [51]?

If after a head injury without loss of consciousness the patients complain of headaches, dizziness, poor concentration, mood disorders or post-traumatic stress disorder, do they indicate a concussion, or do they signify a postconcussional nervous (i.e. psychogenic) reaction without implicating any damage or disorder of the brain [52, 53]?

In the individual case, are so-called post-concussional symptoms [54] psychogenic or physical residua or both? And to what extent are they the result of social or medicolegal manipulation?

Within such a wide framework, does the term concussion carry any clinically useful meaning?

\section{Conclusion}

The term concussion is imprecise. It causes confusion in the minds of both laymen and doctors because its usage refers to different phenomena: (1) the nature of injury, (2) the severity of injury and (3) the extent, if any, of transient functional disorder or structural damage to the brain. The mechanisms remain uncertain. Attempts at definition are unsurprisingly vague but, those supervising sports activities [38] in which the head is injured are expected to apply a comprehensible term within a variety of rules and advice. Concussion is an unsatisfactory term, and cannot be diagnostically appraised unless a strict definition includes a brief period of amnesia and immediate, transient impairment of consciousness after a blow to the head, followed by rapid recovery. But this does not exclude microscopic damage, or destruction of synaptic connections that are not capable of objective demonstration. Nor does it preclude symptomatic after-effects whether physiogenic, psychogenic, or both.
Many observe feeling 'star struck,' or dazed, after a minor blow to the head without even a brief period of loss of consciousness. Whether this constitutes the mildest type of concussion is arguable. It also seems a foolish, circular argument to include the complex symptomatology of post-traumatic or post-concussional syndromes as part of the definition of concussion. It is equally futile to judge post-traumatic symptoms as being functional or organic, psychogenic or physiogenic, for they must always be both. Whether alleged sequelae are mild or severe, many observers agree with Sir Charles Symonds, 'It is questionable whether the effects of concussion, however slight, are ever completely reversible' [33].

It might be added however, that such after-effects are commonly at a cellular or synaptic level, without symptoms, disabilities or impaired quality of life.

Concussion is a term whose meanings and applications have always been controversial, and as our knowledge has increased it should no longer be used in medical circles. Head injuries should be described on the available evidence of the severity and duration of altered consciousness, traumatic amnesia and, when present, the variably associated neurological, psychological, physiological and imaging signs. MTBI is an alternative term that is also somewhat arbitrary in definition.

The millions of minor bumps to the head both in children and adults in which the victim is only momentarily dazed and is completely back to normal within a few seconds or minutes without later clinical sequelae, should remind us of the dangers of the overenthusiastic use of medical labels and their indiscriminate dissemination to the public.

References
1 Ropper AH, Gorson KC: Concussion. New Engl J Med 2007;356:166-172.

2 The American Heritage Science Dictionary: http://dictionary.reference.com/browse/ concussion (accessed 10 February 2007).

3 Trotter W: Certain minor injuries of the brain. Lancet 1924;i:935.

4 http://braininjury.com/littleknownsymptoms.html.

5 Congress of Neurological Surgeons, Committee on Head Injury Nomenclature: Glossary of head injury. Clin Neurosurg 1966;12: 386-394.

6 Denny-Brown D: Cerebral concussion. Physiol Rev 1945;25:296-325.

7 Aubry M, Cantu R, Dvorak J, Graf-Baumann $\mathrm{T}$, et al: Concussion in sport. Summary and agreement statement of the 1st International Conference on Concussion in Sport, Vienna 2001. Br J Sports Med 2002;36:6-7. 
8 Breasted JH: The Edwin Smith Surgical Papyrus. Chicago, University of Chicago Press, 2 vols, 1930.

9 Hippocrates: On wounds in the head; in Hippocrates: Works.London, Loeb Classical Library/Heinemann, 1923-1931. Cited by Flamm, below.

10 Flamm ES: The dilated pupil and head trauma 1517-1867. Med Hist 1972;16:194-199.

11 Gersdorpf H: Feldbuch der Wundartznei. Strassburg, J. Schott, 1517. Cited by Flamm ES, above.

-12 Denny-Brown D, Russell WR: Experimental cerebral concussion. Brain 1941;64:93-164.

13 Berengao de Capri J: Tractatus de fractura calve sive cranei. Bologna, $\mathrm{H}$. de Benedictis, 1518.

14 Paré A: Oeuvres completes (1579). London, Cotes \& Young, 1634.

15 Boirel A: Traité des plaies de tête. Alençon: Martin de la Motte \&veuve Malassis, 1674.

16 Bergmann E von: Die Lehre von den Kopfverletzungen; in Billroth $\mathrm{T}$, Lucke $\mathrm{A}$ : Deutsche Chirurgie, vol 30. Stuttgart, Enke, 1880 .

17 Koch W, Filene W: Beiträge zur experimentellen Chirurgie. Über die commotio cerebri. Arch Klin Chir 1874;17:190-231.

18 Littré M: Histoire de l'academie royale des sciences. Paris, 1705, p 54.

19 Vance BM: Fractures of the skull: complications and causes of Death. A review of five hundred and twelve necropsies and sixtyone cases studied clinically. Arch Surg 1927; 14:1023-1025.

20 Bright R: Reports on Medical Cases Selected with a View of Illustrating the Symptoms and Cure of Diseases by a Reference to Morbid Anatomy. London, Longman, 18271831.

21 Duret H: Traumatisms Craniocérébraux. Accidents Primatifs. Leur Grands Syndromes. Paris, Libraire Felix Alcan, 1920.

22 Berner O: Über kleine, aber tödlich verlaufende traumatische Gehirnblutungen die sogenannten Duret'schen Lesionen. Virchows Arch 1930;277:386-419.

23 Fano S: Memoire sur la commotion du cerveau. Mém Soc Chir (Paris) 1853;3:162.
24 Bryant R: The Practice of Surgery, ed 3. London, Churchill, 1878.

-25 McLatchie G, Jennett B: Head injury in sport. Brit Med J 1994;308:1620-1624.

26 Denny-Brown D, Russell WR: Experimental cerebral concussion. J Physiol 1940;99:153.

27 Oppenheimer DR: Microscopic lesions in the brain following head injury. J Neurol Neurosurg Psychiatry 1968;31:299-306.

28 Adams JH, Corsellis JAN, Duchen LW (eds): Greenfield's Neuropathology, ed 4. London, Arnold, 1984, pp 85-125.

29 Strich SJ: Diffuse degeneration of the cerebral white matter in severe dementia following head injury. J Neurol Neurosurg Psychiatry 1956;19:163-185.

30 Nevin NC: Neuropathological changes in the white matter following head injury. J Neuropathol Exp Neurol 1967;26:77-84.

31 Benson DF, Geschwind N: Shrinking retrograde amnesia. J Neurol Neurosurg Psychiatry 1967;30:539-544.

32 Yarnell PR, Lynch S: Retrograde memory immediately after concussion. Lancet 1970;i:863-864.

33 The World Federation For Neurorehabilitation: Newsletter. http://www.wfnr.co.uk/ pdf/WFNR_autumn_2004.pdf.

34 Shaw NA: The neurobiology of concussion. Progr Neurobiol 2002;67:281-344.

35 Zetterberg H, Hietala MA, Jonsson M, Andreasen N, et al: Neurochemical aftermaths of amateur boxing. Arch Neurol 2006;63: 1277-1280.

36 Symonds CP: Concussion and its sequelae. Lancet 1962;i:1-5.

37 Ommaya AK, Gennarelli TA: Cerebral concussion and traumatic unconsciousness correlation of experimental and clinical observations on blunt head injuries. Brain 1974; 97:633-654.

38 McCrory PR: Were you knocked out? A team physician's approach to initial concussion management. Med Sci Sports Exerc 1997;29 (suppl 7):S207-S212.

39 McCrory P, Johnston K, Meeuwisse W, Aubry M, Cantu R, et al: Summary and agreement statement of the 2nd International Conference on Concussion in Sport, Prague 2004. Br J Sports Med 2005;39:196-204.

40 Kelly JP, Rosenberg JH: Diagnosis and management of concussion in sports. Neurology 1997;48:575-580.
41 Mild Traumatic Brain Injury Committee of the Head Injury Interdisciplinary Special Interest Group of the American Congress of Rehabilitation Medicine. J Head Trauma Rehabil 1993;8:86-87.

42 McCrory PR, Ariens T, Berkovic SF. The nature and duration of acute concussive symptoms in Australian football. Clin J Sport Med 2000;10:235-238.

43 Lovell M, Iverson G, Collins M, et al: Does loss of consciousness predict neuropsychological decrements after concussion? Clin J Sports Med 1999;9:193-198.

44 Leninger B, Gramling S, Farrell A, et al: Neuropsychological deficits in symptomatic minor head injury patients after concussion and mild concussion. J Neurol Neurosurg Psychiatry 1990;53:293-296.

45 Yarnell PR, Lynch S: Retrograde memory immediately after concussion. Lancet 1970;i:863-864.

46 Russell WR: Cerebral involvement in head injury. A study based on the examination of two hundred cases. Brain 1932;55:549-603.

47 Russel WR, Smith A: Post-traumatic amnesia in closed head injury. Arch Neurol 1961; 5:16-29.

48 Levin H, O'Donnell V, Grossman R: The Galveston orientation and amnesia test: a practical scale to assess cognition after head injury. J Nerv Ment Dis 1979;11:675-668.

49 Fisher CM: Concussion amnesia. Neurology $1966 ; 16 ; 826-830$

50 Blonstein JL, Clarke E: Further observations on the medical aspects of amateur boxing. Brit Med J 1957;1:362.

51 Gil S, Caspi Y, Ben-Ari IZ, Koren D, Klein E: Does memory of a traumatic event increase the risk for posttraumatic stress disorder in patients with traumatic brain injury? A prospective study. Am J Psychiatry 2005;162: 963-969.

52 Sbordone RJ, Liter JC: Mild traumatic brain injury does not produce post-traumatic stress disorder. Brain Inj 1995;9:405-412.

53 Ryan LM, Warden DL: Post-concussion syndrome. Int Rev Psychiatry 2003;15:310-316.

54 Evans RW: The postconcussion syndrome: 130 years of controversy. Semin Neurol 1994; 4:32-39. 